\title{
Interferências das ideologias políticas sobre os gastos destinados \\ á gestão ambiental no Brasil
}

\section{Valkyrie Vieira Fabre, Fernando Scheeffer, Leonardo Flach}

\author{
Departamento de Ciências Contábeis \\ Universidade do Estado de Santa Catarina (UDESC) \\ Departamento de Ciências Contábeis \\ Universidade do Estado de Santa Catarina (UDESC)
}

\begin{abstract}
Departamento de Ciências Contábeis e do Programa de Pós-Graduação em Contabilidade (PPGC)
\end{abstract}
Universidade Federal de Santa Catarina (UFSC)

A gestão pública ambiental envolve as políticas e a aplicação de recursos públicos, destinados à preservação, conservação, recuperação e mitigação ambiental. A temática está em expansão, visto o elevado número de publicaçôes em congressos e periódicos, nos últimos anos. Esta pesquisa tem como objetivo analisar a interferência das ideologias políticas sobre os gastos destinados à gestáo ambiental. Trata-se de uma pesquisa quantitativa, descritiva e documental, que aplicou o método de Análise de Cluster, juntamente com os testes Qui-quadrado, Phi e V de Cramer, a partir de dados de contas públicas de municípios brasileiros. Os resultados corroboram com a tese de que há diferenças entre partidos políticos com matrizes teóricas distintas e que isso traz reflexos aos investimentos públicos na área ambiental. Entre os achados, a pesquisa revela que os governos locais aplicam pouco recurso em gestáo ambiental e que os partidos de esquerda investiram mais nesta área. As conclusōes remetem às lacunas de pesquisa da temática.

Palavras-chave: Gestâo ambiental; Ideologia política, Gastos públicos, Contabilidade governamental

\section{Interference of Political Ideologies on the Costs Intended for Environmental Management in Brazil}

The environmental public management involves the policies and the application of public resources, destined to the preservation, conservation, recovery and environmental mitigation. The theme is expanding, given the high number of publications in congresses and periodicals, in recent years. The objective of this research is to analyze the interference of political ideologies on environmental management costs. This is a quantitative, descriptive and documentary research that applied the Cluster Analysis method, together with Cramer's Chi-square, Phi and V tests, based on data from public accounts of Brazilian municipalities. The results corroborate with the thesis that there are differences between political parties with different theoretical matrices and that this brings reflexes to the public investments in the environmental area. Among the findings, research shows that local governments have little recourse to environmental management and that leftist parties have invested more in this area. The conclusions refer to research gaps in this area.

Keywords: Environmental management, Political Views, Public costs, Government accounting 


\section{Interferencias de las ideologías políticas sobre los gastos destinados a gestión ambiental en Brasil}

La gestión pública ambiental involucra las políticas, y la aplicación de recursos públicos destinados a la preservación, conservación, recuperación y mitigación ambiental. La temática está en expansión, dado el elevado número de publicaciones en congresos y periódicos en los últimos años. Esta investigación tiene como objetivo analizar la interferencia de las ideologías políticas sobre los gastos destinados a la gestión ambiental. Se trata de una investigación cuantitativa, descriptiva y documental, en la que se aplicó el método de análisis de cluster. Asimismo, se utilizaron las pruebas Quicuadrado, Phi y V de Cramer a partir de datos de cuentas públicas de municipios brasileños. Los resultados corroboran la tesis de que hay diferencias entre partidos políticos con matrices teóricas distintas y que ello repercute en las inversiones públicas en el área ambiental. Entre los hallazgos, la investigación revela que los gobiernos locales aplican pocos recursos en gestión ambiental y que los partidos de izquierda invirtieron más en esta área. Las conclusiones remiten a los vacíos sobre la temática que quedan por estudiar.

Palabras clave: gestión ambiental, ideología política, gastos públicos, contabilidad gubernamental

\section{Introdução}

Estudos sobre a temática ambiental são realizados em diversos campos do conhecimento, a multidisciplinaridade de pesquisas tem crescido nos últimos anos (Hepper, Hansen, \& Santos, 2016). A preservação, conservação, recuperação e mitigação ambiental, são açôes que fazem parte das políticas públicas de gestão ambiental. O comportamento dos gestores, associado às ideologias dos partidos, está entre os temas emergentes nas discussóes sobre contas públicas e questôes ambientais. Sant'Ana e Moreira (2017), afirmam que estudos sobre a ecologia política tem se expandido nos últimos anos, com o aumento nas publicaçóes em revistas acadêmicas de todo o mundo. Esta pesquisa empírica, apresenta um link relevante entre os aspectos contábeis e políticos, ao analisar o direcionamento ideológico dos gestores na aplicação de recursos públicos em gestão ambiental.

Ferreira, Albino e Freitas (2017), destacam que o Brasil é o décimo país com maior número de vítimas relacionadas aos desastres ambientais. Rosa, Fabre e Dallabona (2018) que analisaram os dados contábeis relativos ao gasto público na função Gestão Ambiental em períodos de enchente e pós-enchente, afirmam que os gestores públicos têm dado pouca importância a este tema, e que a instabilidade e insuficiência de recursos demonstra que o setor ainda está se estruturando e enfrenta restriçóes do ponto de vista político e econômico.

Os desastres ambientais recentes têm chamado a atenção em todo o mundo. No Brasil, catástrofes por enchentes e rompimento de barragens tem assolado a população que cobra ações do governo. A crise política e financeira instaurada no país, estimula a desconfiança do cidadão, em relação a capacidade de resposta frente aos riscos ambientais existentes e a própria gestão dos recursos públicos. Eyerkaufer, Bonfante, Dallabona e Fabre (2019), afirmam que no cenário atual brasileiro os acidentes continuam com índices alarmantes, gerando gastos ao governo, empresas e economia como um todo, além do sofrimento físico e emocional dos envolvidos.

Nakagawa, Relvas e Dias (2007) explicam que a população delega ao ente público parte de seus recursos, gerando a obrigação de prestação de contas através dos pilares da confiabilidade e evidenciação, dando forma ao conceito de accountability. Segundo Braga (2007), 
Brasil, Venezuela e Peru são os países sul-americanos com melhor nível de informatização dos governos, possibilitando disponibilizar ao cidadão uma vasta rede de informaçóes sobre o processo decisório governamental. Flack, Mattos, Will e Roschel (2017), afirmam que o nível de desenvolvimento dos princípios democráticos e da cidadania requer divulgação de informações ao cidadão.

O papel da contabilidade em evidenciar os gastos públicos com gestão ambiental, por meio das demonstraçóes contábeis oficiais, vem sendo cada vez mais relevante para tomada de decisão dos stakeholders. Fabre, Alberton e Pftischer (2012), afirmam que o Brasil possui um ativo natural imensurável, onde o volume de agentes públicos qualificados para o exercício da fiscalização ambiental não corresponde à área territorial de dimensôes continentais, evidenciar é dever dos agentes públicos, interpretar as informaçóes é essencial para o exercício da cidadania. Além disso, a literatura apresenta a prevenção como o melhor caminho, porém, nem sempre os gestores estão conscientes da importância de fazer um planejamento dos riscos (Eyerkaufer et al., 2019).

As decisões quanto às políticas públicas estão nas mãos dos representantes eleitos e a questão ambiental apresenta divergências importantes entre os partidos políticos, levando em conta o aspecto político-ideológico. Nesse contexto a temática ambiental se apresenta como um dos temas pós-materialistas importantes.

Do ponto de vista teórico-conceitual espera-se que partidos de esquerda sejam mais ambientalistas, defendendo uma maior regulação ambiental por parte do Estado, bem como a ampliação de recursos para uma efetiva gestão ambiental. Já para os partidos de direita, em prol do crescimento econômico, a interferência do Estado se demonstraria danosa, cabendo ao mercado autorregular o setor. Não há como negar que, como afirma Thomassen (1999), a dimensão ideológica esquerda/direita é um poderoso instrumento de simplificação e comunicação e, como tal, esta dimensão vem incorporando e absorvendo uma série de conflitos e problemas societários recentes.

A estrutura política administrativa definida pela Constituição Federal Brasileira, em seu artigo $2^{\circ}$, estabelece harmonia entre os poderes Legislativo, Executivo e Judiciário, sendo que, no âmbito municipal limita-se ao exercício dos poderes Legislativo e Executivo. Para Prade e Fabre (2018), o poder Executivo está mais propenso à desconfiança da população brasileira que em 2015 e 2016 saiu às ruas em manifestos, pedindo o fim da corrupção, a melhor aplicação dos recursos públicos, a maior fiscalização do Legislativo e agilidade do Judiciário, na punição de gestores públicos eleitos pelos cidadãos.

Diante de um cenário político conturbado, vivido no Brasil nos últimos, onde dados contábeis e manifestaçóes populares de descontentamento com a gestão motivaram a cassaçáo do mandato eletivo da presidente do país, o entendimento do impacto ideológico na tomada de decisão do gestor, em relação aos recursos públicos existentes, pode influenciar o cidadão na escolha de seus representantes nos próximos pleitos eleitorais.

Atualmente, passou a existir interesse público na verificação da relação entre as supostas diferenças ideológicas dos partidos e o comportamento dos atores políticos em relação à destinação de recursos públicos à gestão ambiental. Neste sentido, cientistas contábeis e cientistas políticos, unem esforços a fim de responder a seguinte questão problema: qual é a interferência das ideologias políticas sobre os gastos públicos destinados à gestáo ambiental? 
Ao utilizar dados contábeis e características ideológicas dos gestores públicos, esta pesquisa busca apresentar um tema relevante e atual, tendo como principal objetivo analisar a interferência das ideologias políticas sobre os gastos destinados à gestão ambiental. A contribuiçáo acadêmica, consiste no preenchimento de uma lacuna de conhecimento, constatada pela revisão da literatura, quando se identificou a escassez de estudos que integrem as áreas de domínio das Ciências Contábeis e Ciência Política, culminando em temas relacionados à gestão pública.

$\mathrm{O}$ artigo foi estruturado em cinco tópicos principais. Iniciou com esta breve introduçáo, seguida do referencial teórico que trata da contabilidade e ideologias políticas com foco ambiental. $\mathrm{Na}$ sequência são definidos os procedimentos metodológicos utilizados para construção do conhecimento. Os resultados e discussões são descritos no tópico quatro e as conclusóes encerram o artigo. Ao final são relacionadas todas as referências utilizadas.

\section{Referencial teórico}

A gestão ambiental pode ser observada sob diversos aspectos, esta pesquisa abordará o tema no setor público, considerando a inter-relação contábil e de decisão ideológica do gestor. Sharma e Henriques (2005), que abordam a questão ambiental e sustentável, investigando gestores em indústrias canadenses, afirmam que recursos aplicados em gestão ambiental trazem desenvolvimento local e global. Mas no setor público, as decisóes emanam de gestores eleitos, sob campanhas que envolvem ideologias distintas.

No Brasil, apesar da base cultural normativa e do vasto patrimônio ambiental existente, não há definição legal de valores mínimos para aplicação de recursos públicos em gestão ambiental, assim, cabe ao gestor eleito a decisão de "abraçar" a questão ambiental.
O referencial teórico abordará dois aspectos da gestão ambiental: o aspecto contábil, quanto a norma brasileira e os conceitos voltados à contabilidade pública e a gestão ambiental; e, o aspecto ideológico do gestor, quanto a distinçáo entre ideologias e suas premissas voltadas à questão ambiental.

\subsection{Contabilidade e Gestão Ambiental}

No contexto público a Ciência Contábil pode contribuir para a gestão dos recursos ambientais por meio dos relatórios das entidades governamentais. Isso permite à sociedade acesso as informaçóes relacionadas à destinação dos recursos públicos, já que a contabilidade pública não evidencia de forma clara essas informaçōes. Os demonstrativos apenas cumprem as legislações, onde os gastos são expressos através da codificação nacional das despesas públicas (Cruz, Marques, \& Ferreira, 2009).

A nomenclatura desta pesquisa considera a similaridade de conceitos entre gastos contábeis e despesas orçamentárias. Entende-se que as despesas orçamentárias são classificações normativas, utilizadas no Brasil para identificar a qualitativo dos gastos públicos. Em se tratando de aplicação de recurso públicos, uma das classificaçôes orçamentárias da despesa pública é a funcional, estabelecida pela Portaria 42/99. Existem 28 funções de governo, dentre elas a função 18 - Gestão Ambiental, que englobados gastos com preservação e conservação ambiental, controle ambiental, recuperação de áreas degradadas, recursos hídricos e meteorologia (Brasil, 2017). A contabilidade pública é responsável por registrar os gastos na correta classificaçâo orçamentária. Os demonstrativos contábeis são publicados nos sites de governo e serão identificados nos procedimentos metodológicos.

Apesar da contabilidade pública ser geradora de informaçóes e facilitar o exercício da accountability, a

Contabilidad y Negocios (15) 30, 2020 / ISSN 1992-1896 
cultura da divulgação das informações contábeis no Brasil está fortemente ligada à normatização legal. A Constituição Federal exige a prévia aprovação legal dos orçamentos públicos; a Lei 4.320/64 determina a divulgação dos balanços públicos; a Lei Complementar 101/00 obriga a divulgação de vários demonstrativos contábeis e estabelece as audiências públicas; a Lei Complementar 131/09 amplia a obrigação da evidenciação dos atos e fatos contábeis que possam interferir no patrimônio público, impondo sançóes institucionais severas; a Lei 12.527/11 instituiu o amplo acesso à informação pelo cidadão, traz avanços significativos no direito a participação e fiscalização popular (Brasil, 2017).

A dimensão dos desastres ambientais pode influenciar no volume de gastos públicos. No Brasil, por ser um país de dimensóes continentais, composto por 26 Estados membros e 1 Distrito Federal, o poder exercido pelos gestores públicos e a definição de suas ações, podem interferir significativamente a vida dos cidadãos. Segundo estudos de Ferreira et al. (2017), o Brasil em 2008, foi apontado pelo Office of U.S. Foreign Disaster Assistance/Centre for Research on the Epidemiology of Disasters, em relação aos 30 desastres ambientais ocorridos no mundo, como o décimo país com maior número de vítimas relacionadas, impactando diretamente nas finanças públicas das regióes atingidas.

\subsection{Ideologias políticas e a questáo ambiental}

Para que se possa entender o que supostamente representam os conceitos de direita e esquerda hoje, o primeiro passo é compreender o surgimento destas terminologias. Elas advêm da Revolução Francesa de 1789, quando se iniciaram os trabalhos para a elaboração da primeira constituição francesa e quando os representantes políticos se posicionaram em luga- res diferenciados nos assentos do plenário. De uma maneira bastante simplificada, é possível afirmar que à esquerda do plenário sentaram-se delegados identificados com o igualitarismo e buscando uma reforma social, ao passo que à direita um grupo identificado com a aristocracia e o conservadorismo (Tarouco \& Madeira, 2013).

Como se pode notar, os termos direita e esquerda, embora etimologicamente tragam uma conotação espacial, em se tratando de ideologias políticas, passaram a denotar perfis político-ideológicos distintos. A tendência mais aceita hoje é a de que a terminologia ainda permanece válida, entretanto é necessário atualizar o seu significado.

Um dos defensores mais conhecidos desse viés é Roberto Bobbio (1995), que afirma que há distinção significativa entre as pessoas neste aspecto e que pode ser sintetizada na dicotomia igualdade versus liberdade. A igualdade para a esquerda deve ser priorizada em detrimento da liberdade que para a direita deve ser conservada. O igualitário parte da convicção de que a maior parte das desigualdades são sociais e, enquanto tais, elimináveis; o inigualitário, ao contrário, parte da convicção oposta, de que as desigualdades são naturais e, por isso, inelimináveis (Bobbio, 1995). Para Giddens (2000) direita e esquerda representam forças distintas em relação a que Estado se quer chegar. A esquerda defende um Estado com dispêndio elevado, ao passo que a direita defende um Estado mínimo. Essa parece ser a discrepância e a disputa fundamental entre a "nova esquerda" e o "novo liberalismo".

Entretanto, como aponta Heywood (2010a), no cerne das mudanças que estamos presenciando, está a transição das sociedades industriais para as pós-industriais. Nas questóes eminentemente materiais ou de sobrevivência, se tornam secundárias para uma proporção 
cada vez maior da população. Em condiçóes mais prósperas, os indivíduos manifestam maior interesse por questôes "pós-materiais". Estão presentes temas como igualdade entre os sexos, paz mundial, harmonia racial, direitos dos animais e proteção ambiental.

Inglehart (1977) é o célebre defensor do chamado pós-materialismo; segundo ele, haveria, após a segunda metade do século XX, uma lenta e gradual mudança de um amplo espectro de valores humanos. Alcançada a segurança material questóes econômicas perdem espaço e dão lugar a questóes pós-materiais, um esforço diferenciado para maximizar o bem-estar no mundo contemporâneo. Passam a fazer parte do debate político e ideológico as questôes como: qualidade de vida em seu sentido amplo, preservação ambiental, possibilidade de auto expressão, dentre outras.

Para Heywood (2010b) as "novas" ideologias diferem das "clássicas" por várias razóes, destacando-se a mudança de enfoque da economia para a cultura. As novas ideologias, enfatizam fatores como gênero, cultura e etnia, diferentemente das ideologias clássicas. Podem ser consideradas novas, pois deram notoriedade sem precedentes à áreas do debate ideológico. Segundo ele, dentre as mais significativas está o que chama de ecologismo e as divergências em relação as origens da crise ecológica contemporânea e de como dar conta da problemática ambiental.

Cunha e Guerra (2003) afirmam que o grande dilema político-ideológico, no que diz respeito ao enfrentamento da questáo ambiental, passa pelas respostas a algumas perguntas como: quais as melhores instituiçóes para a regulaçáo do uso e acesso aos recursos naturais? É possível conciliar intervenção do poder público e auto regulação? Mecanismos de mercado podem auxiliar o controle da exploraçấo dos recursos naturais? $\mathrm{O}$ modo de responder tais questôes denota divergências importantes em relaçáo ao papel do Estado, na proteção ao meio ambiente e na regulação do uso dos recursos naturais.

Em se tratando de exploração dos recursos naturais, para a esquerda a regulaçáo do Estado passou a ser defendida como solução para dar conta da contradição entre os interesses individuais e os interesses coletivos. Os inúmeros certificados ambientais ou selos verdes seriam exemplos de mecanismos privados de regulação ou auto regulação. Como aponta Sachs (1986), para os interesses coletivos, a política ambiental estatal é percebida pelos interesses privados como um empecilho, sendo custosas e uma ameaça ao crescimento econômico. A partir deste ponto de vista a direita teria um enfoque claramente desenvolvimentista aliado à boa administração dos recursos naturais.

Fica a dúvida sobre até que ponto as divergências político-teóricas fazem sentido ao analisar a atuação partidária e a gestão ambiental nos municípios brasileiros, conduzidas por diferentes agremiaçóes partidárias e situadas em nas mais distintas localizaçôes do espectro político.

\section{Procedimento metodológico}

Por meio de uma pesquisa quantitativa, aplicou-se o método de Análise de Cluster, juntamente com os testes qui-quadrado, Phi e $\mathrm{V}$ de Cramer, a partir de dados de todas as capitais brasileiras. A análise de cluster (conglomerados ou agrupamentos) é uma técnica estatística que permite agrupar casos ou variáveis em grupos homogêneos em função do grau de similaridades entre os indivíduos a partir de variáveis predeterminadas. É uma técnica exploratória e permite identificar elementos semelhantes, outliers, bem como levantar hipóteses sobre as associaçôes dos objetos em questão (Fávero \& Belfiore, 2017). O teste 
qui-quadrado compara as frequências observadas com as esperadas em cada categoria. Tanto o teste $\mathrm{V}$ de Cramer, quanto o Phi servem para medir a associação das variáveis. O segundo é semelhante ao $\mathrm{R}$ de Pearson, só que para tabelas $2 \times 2$. O tabela 1 demonstra o constructo da pesquisa, de forma a atingir o objetivo geral de analisar a interferência das ideologias políticas sobre os gastos destinados à gestão ambiental.

A população da pesquisa são os municípios brasileiros, como amostra, optou-se por analisar todas as capitais de estados brasileiros. A escolha pela amostra desta pesquisa se justifica por representar o contexto brasileiro dos grandes colegiados eleitorais e dos municípios com maior concentração de poder político dentro dos Estados. Afinal, são nas capitais as sedes dos poderes Legislativos, Executivo e Judiciários, dos Entes estaduais e municipais. Quanto aos procedimentos foi utilizado o levantamento documental de dados contábeis e vinculaçóes político-partidárias dos Prefeitos.

O período analisado foi para os anos de 2014, 2015 e 2016. Este período foi selecionado porque representa integralmente o mandato do gestor municipal cujo planejamento orçamentário (estabelecido pelo artigo 165 da Constituição Federal de 1988) foi elaborado por sua equipe e sob sua supervisão. Destaca-se que as leis orçamentárias são elaboradas no primeiro ano de mandato e passam a vigorar a partir do segundo ano de mandato. Já o plano plurianual se estende por quatro anos, adentrando ao primeiro ano do mandato subsequente.

As variáveis de gastos públicos orçamentários, foram retiradas do site do Sistema de Coleta de Dados Contábeis (SITN) ou Sistema de Informações Contábeis e Fiscais do Setor Público Brasileiro (SICONFI), que consolidam informaçóes contábeis oficiais da União, Estados, Distrito Federal e Municípios brasileiros. De forma geral, os dados foram extraídos do "Relatório resumido da execução orçamentária de Despesas por Função/Subfunção" e do "Demonstrativo da Receita Corrente Líquida”.

Em relação à classificação dos partidos brasileiros no espectro ideológico (esquerda, centro e direita), a mais usual na Ciência Política é aquela baseada na opinião de especialistas e considerada por muitos

\section{Tabela 1. Constructo da pesquisa}

\begin{tabular}{|c|c|c|c|}
\hline Objetivo específico & Dados selecionados & Formatação & Resultados \\
\hline $\begin{array}{l}\text { 1. Levantar os gastos } \\
\text { públicos com Gestão } \\
\text { Ambiental. }\end{array}$ & $\begin{array}{l}\text { - Gastos da função } 18 \text { - Gestão Ambiental } \\
\text { (Relatório resumido da execução orçamentária } \\
\text { de Despesas por Função/Subfunçáo); } \\
\text { - Valor total da Receita Corrente Líquida - RCL } \\
\text { (Demonstrativo da Receita Corrente Líquida). }\end{array}$ & $\begin{array}{l}\text { Com o software Excel: percentual } \\
\text { da RCL utilizado com Gestáo } \\
\text { Ambiental anualmente e média } \\
\text { dos percentuais do período. }\end{array}$ & $\begin{array}{l}\text { Percentual de } \\
\text { gastos com Gestão } \\
\text { Ambiental no } \\
\text { período em relação } \\
\text { à RCL. }\end{array}$ \\
\hline $\begin{array}{l}\text { 2. Levantar as ideologias } \\
\text { partidárias dos prefeitos } \\
\text { em exercício. }\end{array}$ & $\begin{array}{l}\text { - Ideologia definida por especialistas (Krause, } \\
\text { Machado, \& Michel, 2016); } \\
\text { - Partidos dos prefeitos eleitos (Estadão, 2012). }\end{array}$ & $\begin{array}{l}\text { Com o software Excel: listagem por } \\
\text { ordem de municípios. }\end{array}$ & $\begin{array}{l}\text { Ideologia e partido } \\
\text { do prefeito no } \\
\text { município. }\end{array}$ \\
\hline $\begin{array}{l}\text { 3. Verificar estatistica- } \\
\text { mente a relação entre } \\
\text { gastos ambientais } \\
\text { praticados por ideologia } \\
\text { e por partido político. }\end{array}$ & $\begin{array}{l}\text { - Percentual de gastos municipais com Gestáo } \\
\text { Ambiental no período em relaçáo à RCL; } \\
\text { - Ideologia e partido do prefeito no Município. }\end{array}$ & $\begin{array}{l}\text { Com o software Excel: comparação } \\
\text { dos dados, tabulação cruzada. } \\
\text { Com o software SPPS: teste } \\
\text { qui-quadrado, teste Phi e V de } \\
\text { Cramer; e análise de Cluster. }\end{array}$ & $\begin{array}{l}\text { Interferência entre } \\
\text { as variáveis gastos, } \\
\text { partidos e ideolo- } \\
\text { gias. }\end{array}$ \\
\hline
\end{tabular}


autores como a mais adequada já que eles servem como referência do conhecimento científico acumulado na área (Tarouco \& Madeira, 2015). No geral, os autores pouco divergem em relação à alocação dos partidos nessas categorias. Foi utilizada aqui a classificação realizada para a elaboração do livro "Coligaçóes e disputas eleitorais na Nova República: aportes teórico-metodológicos, tendências e estudos de caso" (Krause, et al., 2016). Trata-se de uma classificação realizada justamente buscando uma padronização a ser utilizada por diversos pesquisadores envolvidos no projeto patrocinado pela Fundaçáo Konrad-Adenauer, que resultou no livro mencionado.

\section{Análise dos resultados}

O objetivo desta pesquisa é analisar a interferência das ideologias políticas sobre os gastos destinados à gestão ambiental. Desta maneira, a apresentação e análise dos dados seguiu a ordem dos objetivos específicos e do constructo da pesquisa definido no tabela 1 .

Em resposta ao objetivo específico 1 - Levantar os gastos públicos com Gestão Ambiental; foi elaborada a tabela 2, que apresenta os percentuais de gastos com gestão ambiental em relação à Receita Corrente Líquida (RCL), calculados conforme descrito na metodologia desta pesquisa.

A tabela 2 demonstra que os gastos com Gestão Ambiental não são muito significativos nos Municípios pesquisados. A média dos gastos é $0,95 \%$ da Receita Corrente Líquida com estas funçóes de governo. Alguns municípios se destacam por aplicar muito mais que a média nacional as capitais.

Para levantar as ideologias partidárias dos prefeitos em exercício, foi elaborada a tabela 3 , que apresenta os partidos e ideologias, identificados conforme descrito na metodologia desta pesquisa.
Tabela 2. Percentual de gastos com Gestão Ambiental em relaçáo à RCL

\begin{tabular}{|c|c|c|c|c|}
\hline Municípios & $\begin{array}{l}\text { Ano } \\
2014\end{array}$ & $\begin{array}{l}\text { Ano } \\
2015\end{array}$ & $\begin{array}{l}\text { Ano } \\
2016\end{array}$ & Média \\
\hline REGIÃO SUL & & & & \\
\hline Porto Alegre - RS & $1,2 \%$ & $1,1 \%$ & $1,1 \%$ & $1,14 \%$ \\
\hline Florianópolis - SC & $0,3 \%$ & $1,3 \%$ & $1,3 \%$ & $0,98 \%$ \\
\hline Curitiba - PR & $2,0 \%$ & $2,5 \%$ & $0,1 \%$ & $1,57 \%$ \\
\hline $\begin{array}{l}\text { REGIÃO CENTRO- } \\
\text { OESTE }\end{array}$ & & & & \\
\hline Campo Grande - MS & $1,7 \%$ & $2,0 \%$ & $1,7 \%$ & $1,82 \%$ \\
\hline Cuiabá - MT & $3,3 \%$ & $0,6 \%$ & $0,1 \%$ & $1,34 \%$ \\
\hline Goiânia - GO & $0,0 \%$ & $0,1 \%$ & $0,1 \%$ & $0,07 \%$ \\
\hline REGIÃO NORTE & & & & \\
\hline Palmas - TO & $0,1 \%$ & $0,1 \%$ & $0,4 \%$ & $0,19 \%$ \\
\hline Boa Vista - RR & $1,2 \%$ & - & $1,4 \%$ & $1,24 \%$ \\
\hline Porto Velho - RO & $0,7 \%$ & $0,7 \%$ & $0,7 \%$ & $0,69 \%$ \\
\hline Belém - PA & $0,7 \%$ & $9,8 \%$ & $0,6 \%$ & $3,72 \%$ \\
\hline Manaus - AM & $0,5 \%$ & $0,5 \%$ & $0,5 \%$ & $0,51 \%$ \\
\hline Macapá - AP & $4,8 \%$ & $5,1 \%$ & $2,7 \%$ & $4,20 \%$ \\
\hline Rio Branco - AC & $2,6 \%$ & - & $4,0 \%$ & $3,17 \%$ \\
\hline REGIÃO SUDESTE & & & & \\
\hline São Paulo - SP & $0,8 \%$ & $0,7 \%$ & $0,6 \%$ & $0,71 \%$ \\
\hline Rio de Janeiro - RJ & $0,8 \%$ & $0,6 \%$ & $0,6 \%$ & $0,68 \%$ \\
\hline Belo Horizonte - MG & $2,6 \%$ & $1,2 \%$ & $1,0 \%$ & $1,60 \%$ \\
\hline Vitória - ES & $3,3 \%$ & $3,3 \%$ & $3,3 \%$ & $3,32 \%$ \\
\hline REGIÃO NORDESTE & & & & \\
\hline Maceió - AL & $0,1 \%$ & $0,3 \%$ & $0,1 \%$ & $0,18 \%$ \\
\hline Salvador - BA & $0,2 \%$ & $0,2 \%$ & $0,4 \%$ & $0,29 \%$ \\
\hline Fortaleza - CE & $1,8 \%$ & $1,6 \%$ & $1,7 \%$ & $1,71 \%$ \\
\hline São Luís - MA & $0,1 \%$ & $5,5 \%$ & $0,0 \%$ & $1,88 \%$ \\
\hline João Pessoa - PB & $0,5 \%$ & $0,3 \%$ & $0,2 \%$ & $0,32 \%$ \\
\hline Recife - PE & $0,6 \%$ & $0,7 \%$ & $0,3 \%$ & $0,54 \%$ \\
\hline Teresina - PI & $0,1 \%$ & $0,1 \%$ & $0,3 \%$ & $0,14 \%$ \\
\hline Natal - RN & $0,1 \%$ & $0,2 \%$ & $0,2 \%$ & $0,15 \%$ \\
\hline Aracajú - SE & $0,7 \%$ & $0,0 \%$ & $0,0 \%$ & $0,23 \%$ \\
\hline
\end{tabular}

Fonte: Elaborada pelos autores com base nos dados da pesquisa.

Contabilidad y Negocios (15) 30, 2020 / ISSN 1992-1896 
Tabela 3. Ideologia e partido político do prefeito

\begin{tabular}{|c|c|c|c|c|c|}
\hline Municípios & Partido & Ideologia & Municípios & Partido & Ideologia \\
\hline REGIÃO SUL & & & REGIÃO SUDESTE & & \\
\hline Porto Alegre - RS & PDT & Esquerda & São Paulo - SP & PT & Esquerda \\
\hline Florianópolis - SC & PSD & Direita & Rio de Janeiro - RJ & PMDB & Centro \\
\hline Curitiba - PR & PDT & Esquerda & Belo Horizonte - MG & PSB & Esquerda \\
\hline REGIÂO CENTRO-OESTE & & & Vitória - ES & PPS & Esquerda \\
\hline Campo Grande - MS & PP & Direita & REGIÃO NORDESTE & & \\
\hline Cuiabá - MT & PSB & Esquerda & Maceió - AL & PSDB & Centro \\
\hline Goiânia-GO & PT & Esquerda & Salvador - BA & DEM & Direita \\
\hline REGIÄO NORTE & & & Fortaleza - CE & PSB & Esquerda \\
\hline Palmas - TO & $\mathrm{PP}$ & Direita & São Luís - MA & PTC & Direita \\
\hline Boa Vista-RR & PMDB & Centro & João Pessoa - PB & PT & Esquerda \\
\hline Porto Velho-RO & PSB & Esquerda & Recife - PE & PSB & Esquerda \\
\hline Belém-PA & PSDB & Centro & Teresina - PI & PSDB & Centro \\
\hline Manaus-AM & PSDB & Centro & Natal - RN & PDT & Esquerda \\
\hline Macapá - AP & PSOL & Esquerda & Aracajú - SE & DEM & Direita \\
\hline Rio Branco-AC & PT & Esquerda & & & \\
\hline
\end{tabular}

Fonte: Elaborada pelos autores, com base nos dados da pesquisa.

A tabela 3 demonstra que a ideologia mais representativa é a/de esquerda com 14 identificações, enquanto o partido com maior número de Prefeitos em exercício nas capitais brasileiras é o PSB, com 5 Municípios.

Para verificar estatisticamente a relação entre gastos ambientais praticados por ideologia e por partido político, foram elaboradas as tabelas e gráficos, que serão apresentados na sequência. Inicialmente, foi elaborada a tabela 4, que apresenta os percentuais médios praticados por partidos e ideologias, identificados conforme descrito na metodologia desta pesquisa.

A tabela 4 demonstra que o maior gasto com Gestão Ambiental é realizado pelos prefeitos vinculados aos partidos de esquerda. De maneira coerente com o que se esperaria teoricamente, centro e direita, respectivamente, gastam menos.
Tabela 4. Percentuais médios de gastos praticados por partido e ideologia

\begin{tabular}{|c|c|c|c|}
\hline Partido & Média de Gastos & Ideologia & Média de Gastos \\
\hline DEM & $0,26 \%$ & \multirow{4}{*}{ Direita } & \multirow{4}{*}{$0,90 \%$} \\
\hline $\mathrm{PP}$ & $1,01 \%$ & & \\
\hline PSD & $0,98 \%$ & & \\
\hline PTC & $1,88 \%$ & & \\
\hline PMDB & $0,96 \%$ & \multirow{2}{*}{ Centro } & \multirow{2}{*}{$1,08 \%$} \\
\hline PSDB & $1,14 \%$ & & \\
\hline PDT & $0,95 \%$ & & \\
\hline PPS & $3,32 \%$ & & \\
\hline PSB & $1,18 \%$ & Esquerda & $1,47 \%$ \\
\hline PSOL & $4,20 \%$ & & \\
\hline $\mathrm{PT}$ & $1,07 \%$ & & \\
\hline
\end{tabular}

Fonte: Elaborada pelos autores com base nos dados da pesquisa. 
No presente estudo e como verificado por Scheeffer (2016) a nível federal, diferente do que é pregado pelo senso comum e corriqueiramente na Ciência Política, a ideologia não parece ser um determinante fraco em tempos atuais. Dentre os temas analisados destaca-se a temática ambiental, sendo este um claro divisor de águas entre esquerda e direita. $\mathrm{O}$ autor analisou votações nominais na Câmara dos Deputados a fim de verificar o peso da ideologia em contraposição ao pertencimento ao governo/oposição. Gerando uma expectativa de comportamento em relação a 24 votações nominais que a princípio dividiram partidos de esquerda e direita, verificou o maior peso da ideologia, sobretudo em "novos" temas que passam a fazer parte do debate político.

Os achados de Scheeffer (2016) não corroboram com os achados de Rodrigues (2010). Ao fazer uma análise quantitativa dos investimentos realizados nos maiores municípios catarinenses durante a gestão 2005-2008, diferente do que previa, há uma tendência relativamente homogênea de variação de gastos entre grupos ideológicos. Assim, a posição ideológica não explica a expansão ou variação dos gastos públicos. Em comum, os diversos grupos ideológicos optaram em ampliar os investimentos no último ano de governo, sobretudo nas áreas mais sensíveis eleitoralmente, não havendo grande distinção entre as prioridades. Desta maneira, o componente ideológico não diferenciaria as administraçóes municipais de forma significativa.

No caso da função Gestão Ambiental, que corresponde as ações desenvolvidas para a consecução de atividades que visam a preservação e conservação do meio ambiente, à época também chamou a atenção os poucos investimentos, independente da ideologia dos partidos dos gestores. De maneira comparativa percebe-se um acréscimo já que em 2005-2008 as gestóes de centro-direita investiram $0,07 \%$, centro-esquerda $0,50 \%$, centro $0,26 \%$, direita-esquerda $0,04 \%$, direita $0,74 \%$, centro-esquerda $0,23 \%$ e esquerda $0,16 \%$.

Em relação aos partidos com menor investimento destaca-se o DEM (0,26\%), não raramente considerado o partido mais à direita do espectro ideológico. A maior diferença de comportamento dos blocos ideológicos se dá no campo da esquerda. PSOL (4,20\%), seguido do PPS (3,32\%), são os partidos que investem mais em gestão ambiental. Levando em conta o comportamento parlamentar na Câmara dos Deputados, para Scheeffer (2016) o PSOL é o partido brasileiro mais ideológico. Tais resultados corroboram com o que afirma Belchior (2010) que ao analisar os chamados partidos "verdes", que defendem causas ecológicas e são bastante presentes no contexto europeu, em quatro sistemas partidários europeus (Bélgica, França, Alemanha e Luxemburgo), o autor destaca que esses partidos normalmente são de esquerda, assim como sugere a literatura. $\mathrm{Na}$ tabela 5, é possível observar a tabulação cruzada entre as variáveis indicador de gastos ambientais e posição ideológica partidária.

Os dados apresentados na tabela 5 demonstram que, de maneira geral, os partidos de esquerda são aqueles que mais têm realizados gastos ambientais. Mesmo assim, os dados também demonstram que os gastos ambientais têm sido baixos ou muito baixos, por parte dos partidos de direita, esquerda e centro.

Para verificar a associaçáo entre as variáveis indicador de gastos ambientais e posição ideológica partidária, aplicou-se o teste qui-quadrado e a razão de verossimilhança. Com base nos dados da tabela 6 , não foi possível rejeitar a hipótese nula, de que não há relação entre as variáveis consideradas.

Contabilidad y Negocios (15) 30, 2020 / ISSN 1992-1896 
Tabela 5. Tabullação cruzada entre indlicador de gastos ambientais e posição ideológica partidária

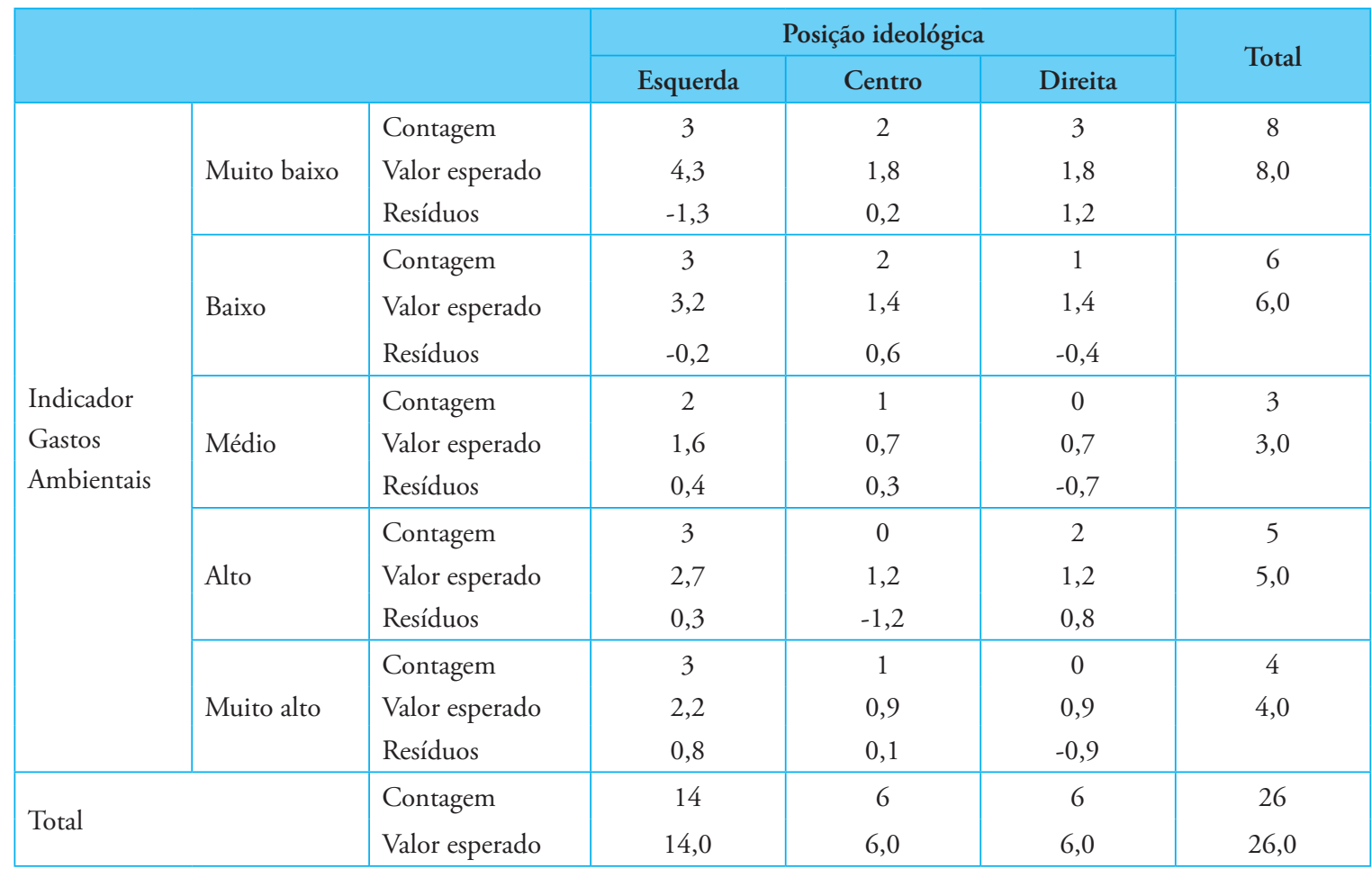

Fonte: Elaborada pelos autores com base nos dados da pesquisa.

Tabela 6. Testes Qui-quadrado entre indicador de gastos ambientais e posiçáo ideológica partidária

\begin{tabular}{|l|c|c|c|}
\hline & Valor & Df & $\begin{array}{c}\text { Sig. Assint. } \\
\text { (2 lados) }\end{array}$ \\
\hline Qui-quadrado de Pearson & $5,520^{\text {a }}$ & 8 & 0,701 \\
\hline Razão de verossimilhança & 8,025 & 8 & 0,431 \\
\hline N. de Casos Válidos & 26 & & \\
\hline
\end{tabular}

Fonte: Elaborada pelos autores com base nos dados da pesquisa.

$\mathrm{Na}$ tabela 7 , estão apresentados os resultados estatísticos dos testes Phi e V de Cramer, aplicados para verificar a ocorrência de associação entre as variáveis indicador de gastos ambientais e posição ideológica partidária. Ambos buscam descrever a intensidade da associação na amostra. $\mathrm{O} V$ de Cramer vai de 0 a 1. O Phi varia de $-1 \mathrm{a}+1$.

Tabela 7. Testes Phi e V de Cramer entre indicador de gastos ambientais e posiçáo ideológica partidária

\begin{tabular}{|l|c|c|c|}
\hline \multicolumn{2}{|c|}{} & Valor & Sig. Aprox. \\
\hline $\begin{array}{l}\text { Nominal por } \\
\text { Nominal }\end{array}$ & Phi & 0,461 & 0,701 \\
\cline { 2 - 4 } & V de Cramer & 0,326 & 0,701 \\
\hline N. de Casos Válidos & 26 & \\
\hline
\end{tabular}

Fonte: Elaborada pelos autores com base nos dados da pesquisa.

A figura 1 representa um gráfico de barras com a associação cruzada entre o indicador gerado de gastos ambientais com a posição ideológica. 
Figura 1. Associaçáo cruzada entre o indicador gerado de gastos ambientais com a posiçáo ideológica

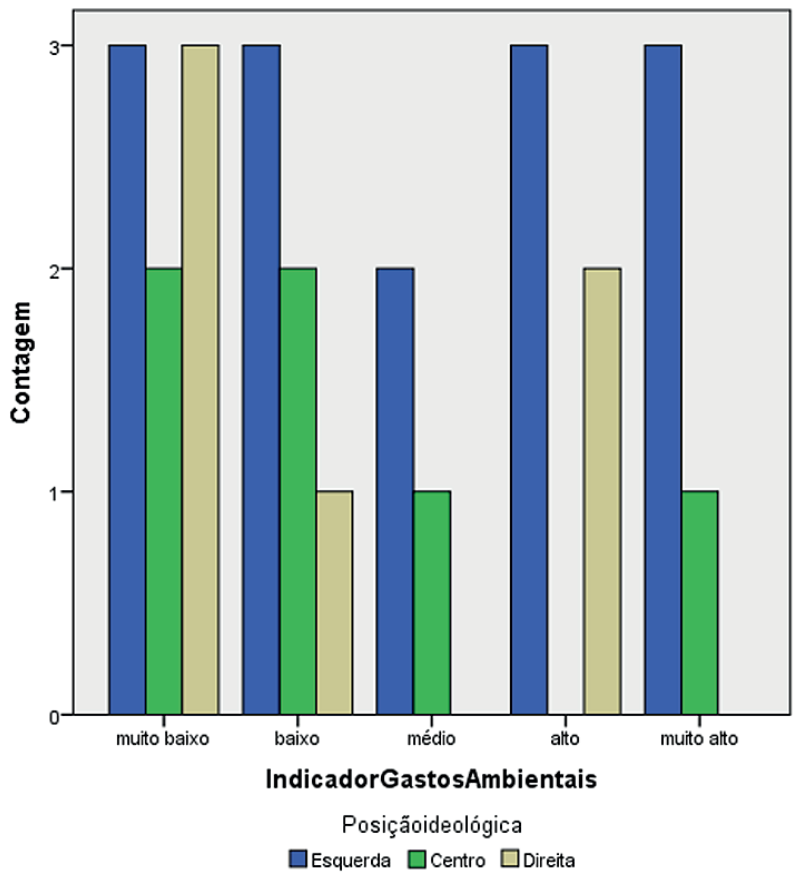

Fonte: Elaborada pelos autores com base nos dados da pesquisa.

O gráfico de barras ilustra que a posição ideológica dos partidos de esquerda está associada aos municípios com maior valor médio de gastos ambientais, como dos municípios com menor valor médio de gastos ambientais. Vale lembrar que este indicador foi elaborado com a seguinte fórmula: média dos gastos com a função gestão ambiental por município (para os anos de 2014, 2015, e 2016), dividido pela média da receita corrente líquida por município brasileiro (para os anos de 2014, 2015, e 2016).

Para verificar a possibilidade de conglomerados de municípios com gastos ambientais e posição ideológica partidária similares, utilizou-se o método estatístico de análise de cluster. $\mathrm{Na}$ tabela 8 , são apresentados os resultados da análise de cluster com as variáveis de gas- tos ambientais entre os anos de 2014 a 2016, e posição ideológica partidária.

Tabela 8. Análise de cluster com as variáveis de gastos ambientais entre os anos de 2014 a 2016, e posiçáo ideológica partidária

\begin{tabular}{|c|c|c|c|c|c|c|}
\hline \multirow{2}{*}{$\begin{array}{l}\text { Está- } \\
\text { gio }\end{array}$} & \multicolumn{2}{|c|}{$\begin{array}{c}\text { Cluster } \\
\text { combinado }\end{array}$} & \multirow{2}{*}{$\begin{array}{l}\text { Coefi- } \\
\text { cientes }\end{array}$} & \multicolumn{2}{|c|}{$\begin{array}{c}\text { O cluster de } \\
\text { estágio é exibido } \\
\text { primeiro }\end{array}$} & \multirow{2}{*}{$\begin{array}{c}\text { Próximo } \\
\text { estágio }\end{array}$} \\
\hline & $\begin{array}{c}\text { Cluster } \\
1\end{array}$ & $\begin{array}{c}\text { Cluster } \\
2\end{array}$ & & $\begin{array}{c}\text { Cluster } \\
1\end{array}$ & $\begin{array}{c}\text { Cluster } \\
2\end{array}$ & \\
\hline 1 & 9 & 15 & 0,000 & 0 & 0 & 5 \\
\hline 2 & 24 & 25 & 0,000 & 0 & 0 & 8 \\
\hline 3 & 7 & 18 & 0,000 & 0 & 0 & 8 \\
\hline 4 & 11 & 23 & 0,000 & 0 & 0 & 17 \\
\hline 5 & 9 & 14 & 0,001 & 1 & 0 & 17 \\
\hline 6 & 3 & 16 & 0,001 & 0 & 0 & 13 \\
\hline 7 & 19 & 22 & 0,001 & 0 & 0 & 10 \\
\hline 8 & 7 & 24 & 0,001 & 3 & 2 & 12 \\
\hline 9 & 4 & 21 & 0,002 & 0 & 0 & 18 \\
\hline 10 & 19 & 26 & 0,004 & 7 & 0 & 14 \\
\hline 11 & 5 & 8 & 0,007 & 0 & 0 & 16 \\
\hline 12 & 6 & 7 & 0,007 & 0 & 8 & 14 \\
\hline 13 & 3 & 20 & 0,012 & 6 & 0 & 18 \\
\hline 14 & 6 & 19 & 0,015 & 12 & 10 & 20 \\
\hline 15 & 13 & 17 & 0,017 & 0 & 0 & 23 \\
\hline 16 & 1 & 5 & 0,018 & 0 & 11 & 19 \\
\hline 17 & 9 & 11 & 0,021 & 5 & 4 & 20 \\
\hline 18 & 3 & 4 & 0,038 & 13 & 9 & 22 \\
\hline 19 & 1 & 2 & 0,065 & 16 & 0 & 22 \\
\hline 20 & 6 & 9 & 0,143 & 14 & 17 & 24 \\
\hline 21 & 10 & 12 & 0,165 & 0 & 0 & 23 \\
\hline 22 & 1 & 3 & 0,242 & 19 & 18 & 24 \\
\hline 23 & 10 & 13 & 0,412 & 21 & 15 & 25 \\
\hline 24 & 1 & 6 & 0,982 & 22 & 20 & 25 \\
\hline 25 & 1 & 10 & 5,930 & 24 & 23 & 0 \\
\hline
\end{tabular}

Fonte: Elaborada pelos autores com base nos dados da pesquisa. 


\section{Figura 2. Número de clusters}

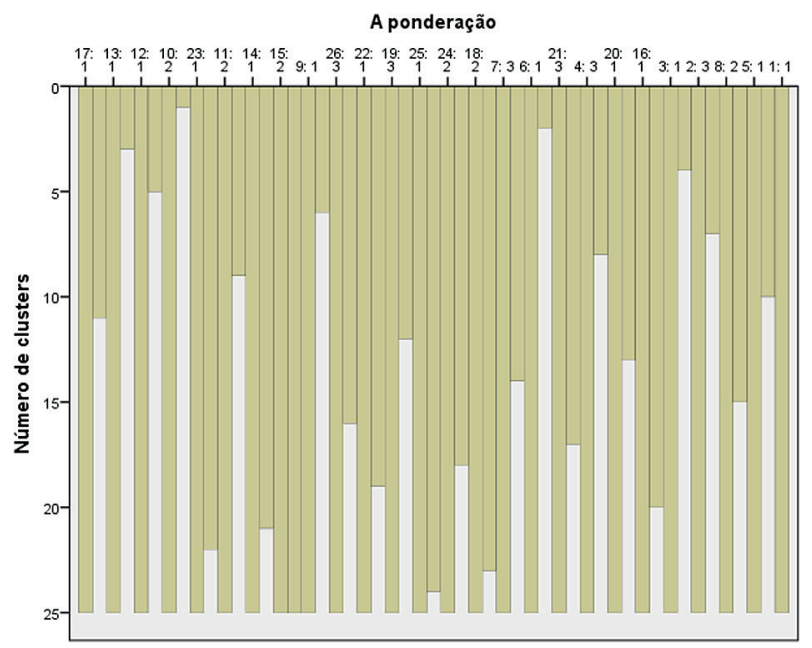

Fonte: Elaborada pelos autores com base nos dados da pesquisa.

A figura 2 destaca uma grande heterogeneidade em relação aos dados. Ou seja, há municípios em que os partidos de esquerda apresentam altos gastos ambientais, e há também municípios com partidos de esquerda destinando poucos recursos para gastos ambientais. $\mathrm{O}$ mesmo fenômeno se repete para os partidos de centro e de direita.

Todavia, com a aplicação do dendograma, no método estatístico de análise de clusters, usando a ligação média entre grupos, mensurada pela distância euclidiana quadrática, foi possível observar a existência de 2 grandes clusters.

A figura 3 também permite observar que, dos dois clusters, há um conglomerado pequeno e um grande. O cluster pequeno consiste nos poucos municípios com alto ou muito alto indicador de gastos ambientais, as ideologias partidárias predominantes são de esquerda e de direita. O cluster grande consiste nos municípios brasileiros com médio, baixo ou muito baixo indicador de gasto ambiental. Os partidos de centro, de maneira geral, permanecem neste grande cluster dos municípios, com baixo ou muito baixo indicador de gastos ambientais.

Figura 3. Dendograma da análise de clusters

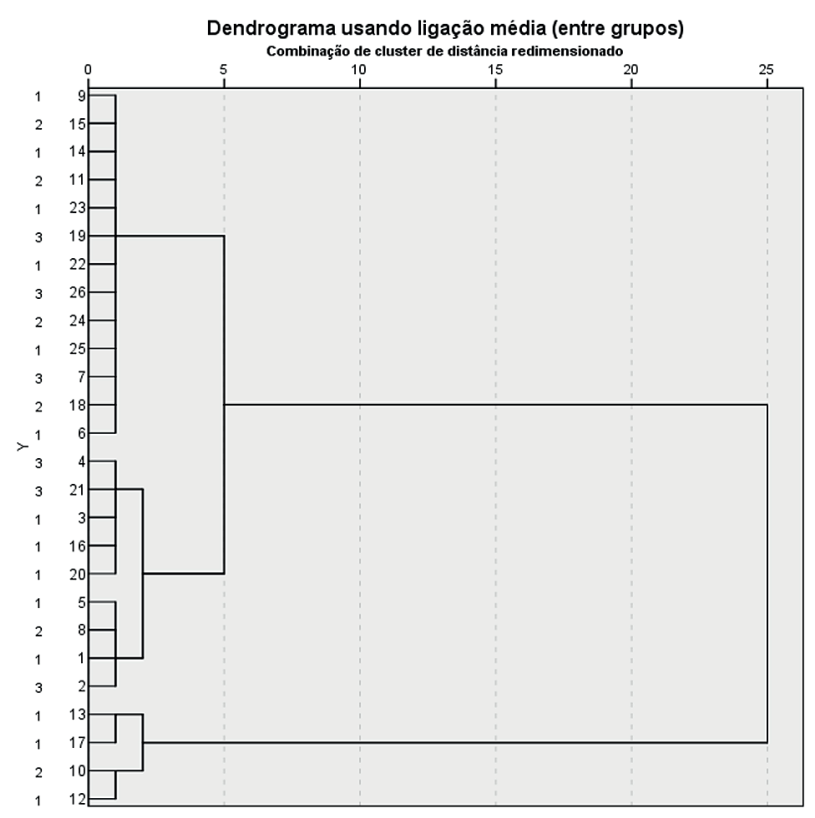

Fonte: Elaborada pelos autores com base nos dados da pesquisa.

\section{Consideraçóes finais}

Diante do que foi exposto a tese de que haveria diferenças entre partidos políticos com matrizes teóricas distintas e que isso traria reflexos nos investimentos públicos parece fazer sentido, pelo menos levando em conta a temática meio ambiente. De qualquer maneira chama a atenção o baixo investimento na área, inclusive em municípios e regiōes que sofrem constantemente catástrofes naturais e problemas ambientais que poderiam ser solucionados com investimentos no setor.

Os resultados corroboram com Scheeffer (2016), que afirma que no debate sobre a reforma do código florestal brasileiro a direita (ruralistas) tende a defender o agronegócio e restriçóes mais amenas, ao passo que a 
esquerda (ambientalistas) propõem maiores restriçóes e puniçōes mais severas ao descumprimento da lei. Em relação aos investimentos em gestão ambiental, aqui pesquisados, o que ocorre se dá de forma análoga. O primeiro grupo dá menos importância para a área ambiental, ao passo que o segundo dá maior importância de investimentos, sem podermos dizer que seja algo prioritário dado os valores ainda ínfimos constatados. Cabe ainda destacar o comportamento dos partidos de centro (PMDB e PSDB), muito próximo aos de direita, ficando a pergunta: se comportando como um partido de direita, faz sentido chamá-los de centro?

Os testes estatísticos realizados nesta pesquisa permitem afirmar que não se pode rejeitar a hipótese nula. Além disso, apesar de se confirmar que a aplicaçáo de recursos na área ambiental é maior em partidos de esquerda, ao analisar os clusters dos períodos de 2014, 2015 e 2016, observa-se a não incidência de conglomerados, visto que há municípios em que os partidos de esquerda gastam pouco recursos em gestão ambiental, assim como há municípios conduzidos por partidos de direita onde se constatou um alto investimento na área. Desta forma, percebe-se uma relevante heterogeneidade nos resultados.

A tese que vigora atualmente é a de que a ideologia, sobretudo em tempos recentes, passou a ser um determinante fraco do comportamento político. Uma possível explicação talvez esteja no fato de que, como aponta Panebianco (2005), mudam-se os termos das divisóes políticas. Se no passado a principal distinção estava relacionada ao quanto de intervenção na economia ou então, políticas a favor do trabalho ou do "capital", a partir dos anos 70 os dilemas passam a ser outros. Empiricamente, no entanto, é possível constatar que atitudes de esquerda e direita estáo diretamente relacionadas a clivagens políticas existentes e diferentes em cada país. Em Taiwan, estas orientaçóes estão ligadas a divergências em relação à independência do país e às relaçóes com a China. No México, a questão da corrupção e mais recentemente o cartel de drogas são importantes. A variável cultural como igualdade de gênero e tolerância social tem praticamente o mesmo peso da variável econômica e é uma clivagem fortemente relacionada com as posiçóes de esquerda e direita hoje. A variável ambiental tem menor peso. No geral, a dimensão esquerda e direita consegue fazer um bom mapeamento das divergências político-ideológicas, inclusive internacionalmente (Dalton, Farrell, \& Mcallister, 2011).

Como apontado por Scheeffer (2016), talvez as maiores clivagens entre esquerda e direita hoje se encontrem em temas que excedem a velha discussão relativa a mais ou menos Estado. Vão além do maior ou menor intervencionismo, seja ele econômico ou social. Óbvio que nem todos "novos" temas são totalmente desconexos com os "velhos" como talvez se possa imaginar. Em se tratando de questóes morais, é notória uma independência que não é constatada, por exemplo, em se tratando de questóes ambientais, em que a divergência pode estar em se defender uma maior ou menor regulaçấo estatal do setor, por exemplo.

A pesquisa cumpriu os objetivos a que se propôs, de analisar a interferência das ideologias políticas sobre os gastos destinados à gestão ambiental. Dois aspectos devem ser considerados a partir desta pesquisa. O primeiro é que o "novos temas" passem a fazer parte do debate político, incluindo divergências em relação ao multiculturalismo, feminismo, temas morais ligados ao conservadorismo e formas de enfrentamento da problemática ambiental. Se os partidos políticos perseguem objetivos e a ideologia é o melhor indicador destes, faz-se necessário mais estudos a fim de verificar o quanto que a terminologia esquerda e direita 
se demonstra atual e o quanto que acabam por interferir naquilo que é fundamental: o comportamento dos atores políticos. O segundo é que a contabilidade pública como geradora, armazenadora e difusora de informações importantes das finanças públicas, pode se aliar a campos multidisciplinares, e proporcionar interpretaçóes sob à luz de diversas teorias, a fim de facilitar a compreensão das informaçóes públicas aos stakeholders, aqui considerados principalmente os cidadãos.

A temática ambiental relacionada à aplicação de recursos públicos ainda tem lacunas de pesquisa a serem exploradas. Cabe aos pesquisadores, principalmente aos do Campo de Públicas, esclarecer algumas questôes ainda não discutidas com profundidade, como: Por que grande parte dos recursos são aplicados na fiscalização, em detrimento de outras subáreas da gestão ambiental? Qual a importância da destinação de recursos à gestáo ambiental dentro do orçamento público? Que outros fatores, além dos ideológicos estão influenciando no direcionamento dos recursos públicos? Que tipo de receitas são geradas a partir de um meio ambiente mais equilibrado? Como as políticas de proteção risco estão impactando nos gastos com gestão ambiental? Estas e outras perguntas ainda precisam de respostas científicas.

\section{Referências}

Belchior, A. M. (2010). Are Green Political Parties More Post-Materialist than Other Parties? An Assessment of Post-Materialist Forecasts. European Societies, 12(4), 467-492. https://doi.org/10.1080/14616696.2010.4 83003

Bobbio, N. (1995). Direita e esquerda: razóes e significados de uma distinção politica. São Paulo: Editora da UNESP.

Braga, S. S. (2007). Podem as novas tecnologias de informação e comunicação auxiliar na consolidação das democracias? Um estudo sobre a informatização dos órgãos legislativos na América do Sul. Opinião Pública, 13(1), 1-50. https://doi.org/10.1590/S010462762007000100001

Brasil (2017). Legislação Federal. Apresenta a legislação federal do Brasil atualizada de acordo com as publicaçōes do Diário Oficial da Uniāo. Recuperado de http://www4. planalto.gov.br/legislacao [Consulta: 10 de outubro de 2017].

Cruz, C. F., Marques, A. L., \& Ferreira, A. C. S. (2009). Informaçôes Ambientais na contabilidade pública: Reconhecimento de sua importância para a sustentabilidade. Revista Sociedade, Contabilidade e Gestão, 4(1), 47-60. https://doi.org/10.21446/scg_ufrj.v4i2.13176

Cunha, S. B., \& Guerra, A. J. T. (2003). A questão ambiental: diferentes abordagens. Rio de Janeiro: Bertrand, Brasil.

Dalton, R. J., Farrell, D., \& Mcallister, I. (2011). Political Parties and Democratic Linkage. Oxford: Oxford University Press. https://doi.org/10.1093/acprof:oso bl/9780199599356.001.0001

Estadão. (2012). Veja os prefeitos eleitos em todas as capitais. Recuperado de http://www.estadao.com.br/noticias/ geral,saiba-mais-veja-os-prefeitos-eleitos-em-todas-ascapitais, 952546 [Consulta: 12 de novembro de 2017].

Eyerkaufer, M. L., Bonfante, E. A., Dallabona, L. F., \& Fabre, V. V. (2019). Simulador de custos para gestão de riscos de acidentes de trabalho. Revista Catarinense da Ciência Contábil, 18, 1-16. https://doi. org/10.16930/2237-766220192753

Fabre, V. V., Alberton, L., \& Pftischer, E. D. (2012). Relevância econômica da perda de água tratada: análise dos dez maiores municípios produtores de Santa Catarina. Revista de Contabilidade do Mestrado em Ciências Contábeis da UERJ, 16(3), 65-80. Recuperado de http:// www.atena.org.br/revista/ojs-2.2.3-06/index.php/ UERJ/article/viewArticle/1280 [Consulta: 12 de novembro de 2017]. 
Fabre, V. V., Scheeffer, F., Dallabona, L. F., \& Kroetz, M. (2017). Théorie des choix publics: analyse de l'influence político-ideologique dans l'application des ressources en gestion environnementale des municipalités brésiliennes touchées parles catastrophes naturelles hidrologiques. Anais do Congrès de l'Institut Franco-Brésilien d'Administration des Entreprises. Poitiers, França, 9.

Fávero, L. P., \& Belfiore, P. (2017). Manual de análise de dados: estatística e modelagem multivariada com Excel, SPSS e Stata. Rio de Janeiro: Elsevier.

Ferreira, D., Albino, L., \& Freitas, M. J. C. C. (2017). Mapeamento participativo para a gestáo de risco de desastres: região dos baús, Ilhota - SC. Revista Brasileira de Cartografia, 69(4), 713-730. Recuperado de http:// www.seer.ufu.br/index.php/revistabrasileiracartografia/article/view/44330 [Consulta: 12 de novembro de 2017].

Flack, L., Mattos, L. K., Will, A. R., \& Roschel, L. F. (2017). Efficiency of Expenditure on Education and Learning by Brazilian States: A Study with Data Envelopment Analysis. Contabilidad y Negocios, 12(23), 111-128. https://doi.org/10.18800/contabilidad.201701.008

Giddens, A. (2000). A terceira via: reflexóes sobre o impasse político atual e o futuro da social-democracia. Rio de Janeiro: Record.

Hepper, E. L., Hansen, P. B., \& Santos, J. L. S. (2016). Iniciativas sustentáveis e desempenho organizacional: uma análise das publicaçôes na base Web of Science. Revista de Gestão Ambiental e Sustentabilidade, 5(2), 98-114. https://doi.org/10.5585/geas.v5i2.410

Heywood, A. (2010a). Ideologias politicas: do liberalismo ao fascismo. São Paulo: Ática.

Heywood, A. (2010b). Ideologias politicas: do feminismo ao multiculturalismo. São Paulo: Ática.

Inglehart, R. (1977). The Silent Revolution. Princeton: Princeton University Press.
Krause, S., Machado, C., \& Miguel, L. F. (2016). Coligaçôes e disputas eleitorais na Nova República: aportes teórico-metodológicos, tendências e estudos de caso. Rio de Janeiro/São Paulo: Fundação Konrad Adenauer/ Editora EDUNESP.

Nakagawa, M., Relvas, T. R. S., \& Dias, J. M. (2007). Accountability: a Razão de ser da Contabilidade. Revista de Educação e Pesquisa em Contabilidade, 1(3), 83-100 https://doi.org/10.17524/repec.v1i3.17

Panebianco, A. (2005). Modelos de partido: organização e poder nos partidos politicos. São Paulo: Martins Fontes.

Prade, A., \& Fabre, V. V. (2018). Gastos com pessoal no poder legislativo municipal: comparativo nos municípios catarinenses. Revista de Contabilidade da UFBA, 12(2), 60-78. https://doi.org/10.9771/rc-ufba. v12i2.18326

Rodrigues, G. (2010). Partidos politicos e gastos públicos em Santa Catarina: a influência das ideologias partidárias nas decisóes de investimentos (tese de doutorado). Universidade Federal de Santa Catarina, Centro de Filosofia e Ciências Humanas. Florianópolis, Brasil. Recuperado de https://repositorio.ufsc.br/ handle/123456789/93997 [Consulta: 12 de novembro de 2017].

Rosa, G. R., Fabre, V. V., \& Dallabona, L. F. (2018). Gastos ambientais nos municípios catarinenses: o que mudou após os desastres naturais ocorridos nos últimos anos? Revista Livre de Sustentabilidade e Empreendedorismo, 3(4), 24-50. Recuperado de http://www.relise.eco.br/ index.php/relise/article/viewFile/164/153 [Consulta: 23 de agosto de 2019].

Sachs, I. (1986). Espaços, tempos e estratégias de desenvolvimento. São Paulo: Vértice.

Sant'Anna, F. M., \& Moreira, H. M. (2017). Ecologia política e relaçóes internacionais: os desafios da Ecopolítica Crítica Internacional. Revista Brasileira de Ciência Política, 20(1), 205-248. https://doi. org/10.1590/0103-335220162006 
Scheeffer, F. (2016). Ideologia e comportamento parlamentar na Câmara dos Deputados: faz sentido ainda falar em esquerda e direita? (tese de doutorado) Universidade Federal de Santa Catarina, Centro de Filosofia e Ciências Humanas. Florianópolis, Brasil. Recuperado de https://repositorio.ufsc.br/ handle/123456789/172579 [Consulta: 8 de janeiro de 2019].

Sharma, S., \& Henriques, I. (2005). Stakeholder Influences on Sustainability Practices in the Canadian Forest Products Industry. Strategic Management Journal, 26(2), 159-180. https://doi.org/10.1002/smj.439

Tarouco, G. S., \& Madeira, R. M. (2013). Partidos, programas e o debate sobre esquerda e direita no Brasil. Revista Sociologia Politica, 21(45), 149-165. https:// doi.org/10.1590/S0104-44782013000100011
Tarouco, G. S., \& Madeira, R. M. (2015). Os partidos brasileiros segundo seus estudiosos: análise de um expert survey. Civitas, 15(1), 24-39. https://doi. org/10.15448/1984-7289.2015.1.18077

Thomassen, J. J. A. (1999). Political Communication between Political Elites and Mass Publics: The Role of Belief Systems. In W. E. Miller, R. Pierce \& J. Thomassen (eds.), Policy Representation in Western Societies (pp. 33-58). Oxford: Oxford University Press.

Fecha de recepción: 03 de octubre de 2019 Fecha de aceptación: 20 de julio de 2020 Correspondencia: valkyrie.fabre@udesc.br fernando.scheeffer@udesc.br leonardo.flach@gmail.com 